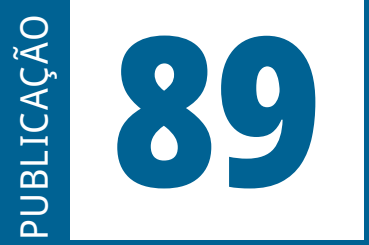

ISSN: 0101-9562

ISSN ELETRÔNICO: 2177-7055

SEQÜÊNCIA

Publicação do

Estudos jurídicos

e políticos

Programa de Pós-Graduação em Direito da UFSC

VOLUME 42 - ANO 2021 
SEQUÊNCIA - ESTUDOS JURÍDICOS E POLÍTICOS é uma publicação temática e de periodicidade quadrimestral, editada pelo Programa de Pós-Graduação Stricto Sensu em Direito da Universidade Federal de Santa Catarina - UFSC.

SEQUÊNCIA - ESTUDOS JURÍDICOS E POLÍTICOS is a thematic publication, printed every four months, edited by the Program in law of the Federal University of Santa Catarina - UFSC.

Versão eletrônica: http://www.periodicos.ufsc.br/index.php/sequencia

A publicação é indexada nas seguintes bases de dados e diretórios/

The Publication is indexed in the following databases and directories:

Base OJS

Base PKP

CCN (Catálogo Coletivo Nacional)

Dialnet

DOAJ (Directory of Open Access Journals)

EBSCOhost

Genamics Journalseek

ICAP (Indexação Compartilhada de Artigos de Periódicos)

Latindex

LivRe!

OJS
PKP
Portal de Periódicos UFSC
Portal do SEER
ProQuest
SciELO
Sherpa/Romeo
Sumarios.org
ULRICH'S
vLex

Ficha catalográfica

Seqüência: Estudos jurídicos e políticos. Universidade Federal de Santa Catarina.

Programa de Pós-Graduação em Direito. n.1 (janeiro 1980)-.

Florianópolis: Fundação José Boiteux. 1980-.

Publicação contínua

Resumo em português e inglês

Versão impressa ISSN 0101-9562

Versão on-line ISSN 2177-7055

1. Ciência jurídica. 2. Teoria política. 3. Filosoia do direito. 4. Periódicos.

I. Universidade Federal de Santa Catarina. Programa de Pós-graduação em

Direito

CDU 34(05)

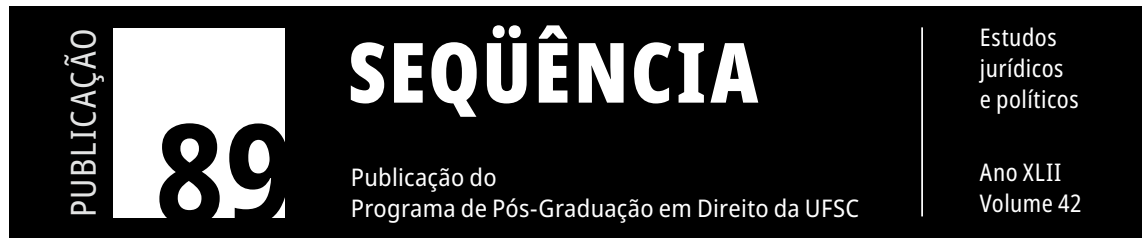




\title{
A implementação dos postulados da justiça restaurativa no âmbito criminal brasileiro
}

\author{
The implementation of the posts of \\ restorative justice within brazilian criminal
}

\author{
Alexandre Ribas de Paulo ${ }^{1}$ \\ ${ }^{1}$ Universidade Estadual de Maringá, Maringá, Brasil \\ Valine Castaldelli Silva ${ }^{2}$ \\ ${ }^{2}$ Centro Universitário Ingá, Maringá, Brasil
}

RESUMO: O presente trabalho tem como objetivo analisar os discursos normativos pertinentes à Justiça Restaurativa no âmbito criminal. A problemática se situa nos termos da Resolução n ${ }^{\circ} 225$, de 31 de maio de 2016, do Conselho Nacional de Justiça, que se propõe a regulamentar o assunto no âmbito jurisdicional no Brasil. Adotando-se o método indutivo, marco teórico concernente à arqueologia foucaultiana e, com análise de documentos e revisão bibliográfica, chega-se à conclusão que o Poder soberano, durante séculos, interditou os acordos intersubjetivos e impôs o monopólio da jurisdição penal e, contemporaneamente, com o surgimento dos postulados internacionais da Justiça Restaurativa, o Conselho Nacional de Justiça, mesmo sem competência para legislar sobre matéria penal e processual penal, tenta se apropriar e controlar as práticas de resolução de conflitos que deveriam ocorrer fora do âmbito formal do Estado.

Palavras-chave: Justiça Restaurativa - Conselho Econômico e Social da ONU Conselho Nacional de Justiça.

ABSTRACT: The objective of the present work is to analyse the normative discourses pertinent to Restorative Justice within brazilian criminal in accordance with Resolution n. 225 of 31th May 2016 of the National Council of Justice, which proposes to regulate the theme in Brazil. This research uses the inductive approach, with document analysis and literature review techniques. This article theoretical 
framework harmonises with Foucault's archaeology. This work concludes that the sovereign power, for centuries, prohibited intersubjective agreements and imposed the monopoly of criminal jurisdiction and, at the same time, as the emergence of the international postulates of Restorative Justice, the National Council of Justice, even without competence to legislate on matters of criminal and criminal procedure, tries to appropriate and control the practices of conflict resolution that should occur outside the formal scope of the State.

KEYwORDS: Restorative Justice - UN Economic and Social Council - National Council of Justice.

\section{INTRODUÇÃO}

O presente trabalho tem como objetivo compreender os paradigmas teóricos, expectativas práticas e métodos de implantação das propostas internacionais pertinentes à Justiça Restaurativa (JR) na jurisdição criminal brasileira, tendo como base o postulado do monopólio do ius puniendi por parte do Estado e o discurso da Resolução no 225, de 31 de maio de 2016, do Conselho Nacional de Justiça $(\mathrm{CNJ})$; além de outros atos regulatórios propostos nas práticas jurídicas brasileiras.

A problemática surge diante da possível incompatibilidade entre os efeitos dos acordos restaurativos e os princípios iluministas no âmbito criminal vigentes no Brasil, em que o Estado soberano seria a vítima constante das infrações penais e doutrina o princípio da obrigatoriedade quanto à ação penal pública que impele o Ministério Público ao oferecimento da denúncia em juízo para prestação da jurisdição penal.

Ocorre que os métodos consensuais de resolução de conflitos preconizados pela Resolução no 2002/12, do Conselho Econômico e Social da Organização das Nações Unidas (CESONU), primeiramente mencionado na redação dada pela Emenda $n^{\circ}$ 01, de 31 de janeiro de 2013 ao artigo $7^{\circ}, \mathbb{S} 3^{\circ}$, da Resolução $n^{-}$125/2010 do CNJ, propõe que o processo restaurativo relativo às infrações penais seja implementado e conduzido de maneira extraprocessual, isto é, na própria comunidade e não na senda monopolizada da Justiça estatal. 
A despeito do mencionado artigo da Resolução n⿳0 125/2010CNJ ter sido revogado pela Emenda no 2, de 08 de março de 2016 e surgir a Resolução no 225-CNJ, datada de 31 de maio de 2016, dispondo sobre a "Política Nacional de Justiça Restaurativa no âmbito do Poder Judiciário", permanece a aporia teórica sobre as consequências jurídico-penais oriundas dos procedimentos restaurativos, suscitando a principal hipótese a serem explorada no presente trabalho: a Resolução no 225/2016 - CNJ, além de ter sua validade questionada perante o princípio da reserva legal também seria débil em suas instruções, não permitindo a JR efetiva no âmbito criminal brasileiro.

O método adotado é o indutivo (Cf. Mezzaroba; Servilha, 2004, p. 62; Alves, 2002, p. 119; Cervo; Bervian, 1976, p. 68) e o marco teórico é o modelo proposto por Michel Foucault ${ }^{1}$, isto é uma arqueologia ${ }^{2}$ com uma descrição sistemática do próprio discurso jurídico e sua teoria, com apoio em autores especialistas em direito criminal e base em revisão bibliográfica.

Em um primeiro momento serão apontadas as características das experiências penais no ocidente medieval, que primava pela composição e transação intersubjetivas como mecanismos de resolução de conflitos extintivos da punibilidade e o momento do estabelecimento do atual paradigma penal moderno como sendo o ius puniendi uma atribuição exclusiva do Estado.

Em seguida se procurará compreender as propostas e postulados teóricos da JR e como que seria a implantação desse tipo de resolução de conflitos intersubjetivos perante a justiça criminal.

Sobre o marco teórico foucaultinao, consultar: VEYNE, 1998, p. 252; BURKE, 1992, p. 08-10; WOLKMER, 2007, p. 13-41.

2 No sentido foucaultiano, a arqueologia visa "definir [...] os próprios discursos, enquanto práticas que obedecem às regras [...]; [definir] os discursos em sua especificidade; mostrar em que sentido o jogo das regras que utilizam é irredutível a qualquer outro" e, sobretudo, ela "não é o retorno ao próprio segredo da origem; é a descrição sistemática de um discurso-objeto." (FOUCAULT, 2000, p. 159-60). 
Finalmente, se procurará apresentar as tentativas normativas para implementação da JR no âmbito penal brasileiro.

\section{CENTRALIZAÇÃO POLÍTICA VERSUS RESOLUÇÃO DE CONFLITOS INTERSUBJETIVOS}

O Brasil não prima pela originalidade de seus institutos políticos e jurídicos, buscando, amiúde, em experiências normativas alheias, métodos de administração de seus jurisdicionados para manter um ideal de controle e disciplina de uma sociedade plural sob o manto de um discurso positivista, porém indeterminado, de "ordem e progresso".

No presente item tentar-se-á vislumbrar uma noção história, amplíssima, sobre a política de centralização política e mecanismos intersubjetivos de resolução de conflitos que ocorreram na Europa ocidental, com o fim de se compreender que são táticas de administração de justiça que se apresentam, a princípio, antagônicas e que os séculos mostraram o embate entre ambas. A síntese dessas experiências jurídico-políticas pode ser percebida no Brasil desde a sua independência.

Sem adentrar na miríade de culturas jurídicas do mundo antigo, o mais significativo para o presente estudo é o estabelecimento do Império Romano, em 27 a.C., como um regime político centralizador, que fez com que os poderes exercidos tradicionalmente pelos pater famílias fossem transferidos para o princeps ("primeiro cidadão" - um dos títulos do Imperador), tornado o ius puniendi, paulatinamente, uma das atribuições exclusivas do Império; deslegitimando, por consequência, os mecanismos domésticos de resolução de conflitos entre os cidadãos. (Cf. Mommsen, 1999, p. 16-7; Cerami; Corbino; Metro; Purpura, 1996, p. 224-5 e 257-8; Cicco, 1993, p. 27; Nisbet, p. 52).

A centralização máxima dos poderes legislativos nas mãos do Imperador teve como marco principal o governo de Diocleciano (284-305) na chamada Tetrarquia; e a continuação da política de centralização administrativa se deu no governo de Constantino (306- 
337), que passou a ser considerado o detentor exclusivo das normas jurídicas, o único definidor das leis, a fonte viva do Direito. Tais caraterísticas podem ser hauridas do discurso normativo compilado por Justiniano, no século VI:

D.1.3.31 Princeps legibus solutus est: Augusta autem licet legibus soluta non est, princeps tamen eadem illi privilegia tribuunt, quae ipsi habent. (Justinianus, 2009, p 57) ${ }^{3}$

D.1.4.1pr Quod principi placuit, legis habet vigorem: utpote cum lege regia, quae de imperio eius lata est, populus ei et in eum omne suum imperium et potestatem conferat. (JustiniaNUS, 2009, p 61). ${ }^{4}$

Importante compreender, porém, que práticas de acordos intersubjetivos não seriam contrários ao pensamento cristão já incorporado pelo Império Romano no decorrer do século V. Ao revés, na versão do Evangelho segundo Matheus, Capítulo 5, versículo 25 (Bíblia, s.d.), há a seguinte exortação: "esto consentiens adversario tuo cito dum es in via cum eo ne forte tradat te adversarius judici et judex tradat te ministro et in carcerem mittaris". ${ }^{5}$ Portanto, mesmo que se imagine uma centralização política desejada e registrada nos documentos administrativos do Império Romano (fontes primárias), o pluralismo jurídico seria uma realidade ampla entre as pessoas iletradas.

3 Tradução de Hélcio Maciel França Madeira: “O príncipe não está sujeito às leis. Embora sua esposa Augusta não esteja livre das leis, os príncipes, todavia, atribuem a ela os mesmos privilégios que eles próprios possuem." Como explica Pietro Cerami (In: CERAMI; CORBINO; METRO; PURPURA, 1996, p. 276-7): “Caratteristica fondamentale della monarchia assoluta è la concentrazione di tutti i poteri nelle mani dell'imperatore. Egli non è più um organo della costituzione, definito princeps, in quanto primo fra i cittadini, ma si pone in un certo senso al di fuori della costituzione, essendo considerato dominus et deus".

4 Tradução de Hélcio Maciel França Madeira: O que agrada ao príncipe tem força de lei. Isso porque o povo, por uma lei régia que foi promulgada sobre o imperium dele, confere a ele todo o seu imperium e sua potestas.

5 Livre Tradução: Concorde com o teu adversário, enquanto estás no caminho com ele para que não aconteça que o adversário te entregue ao juiz, e o juiz te entregue ao oficial, e sejas enviado ao cárcere. 
No Tocante aos povos denominados bárbaros, especialmente no que concerne aos grupos germânicos - sociedades tradicionais ${ }^{6}$ - que se estabeleceram nos territórios do entinto Império Romano do Ocidente, há indícios que eles possuíam práticas que muito se aproximam aos postulados contemporâneos da Justiça Restaurativa, pois a resolução dos conflitos aconteceria, como explica Nilo Batista (2002, p. 33), entre os próprios interessados e seus familiares, seja por meio da renúncia à punição, da composição ou da guerra privada. Do historiador romano Tácito (2001), no século I, nota-se em seu capítulo XII da obra Germania.:

Sed et levioribus delictis pro modo poena: equorum pecorumque numero convicti multantur. Pars multae regi vel civitati, pars ipsi, qui vindicatur, vel propinquis eius exsolvitur. Eliguntur in isdem conciliis et principes, qui iura per pagos vicosque reddunt; centeni singulis ex plebe comites consilium simul et auctoritas adsunt. ${ }^{7}$

Michel Foucault (2005, p. 57), ao comentar a importância da transação penal - acordo direto entre os litigantes - no alto medievo pondera que, como o Direito germânico não fazia uma oposição entre Direito e guerra, a "liquidação judiciária” (resolução do conflito) seria feita como se fosse uma continuação da luta entre os indivíduos e, porquanto, haveria a possibilidade dos contendores chegarem a um acordo, isto é, uma composição dos danos, interrompendo as "hostilidades regulamentadas".

6 Nas palavras de Norbert Rouland (2003, p. 96): "As sociedades tradicionais oferecem numerosos exemplos em que a ausência do Estado não tem como corolário a anarquia e o reinado da violência cega." Para tal autor, sociedades tradicionais seriam justamente aquelas em que não há atividade reitora estatal na administração dos conflitos intersubjetivos.

7 Tradução de João Penteado Erskine Stevenso: E há para os delitos mais leves a penalidade correspondente: em certa quantidade de cavalos e gado são multados os condenados. Parte da multa pertence ao rei ou à cidade, parte ao próprio ofendido, ou aos seus próximos (parentes). Elegem em as mesmas assembléias os chefes, a quem cumpre administrar justiça nas aldeias e (cantões) povoados; cada um possui cem assessores populares para assisti-los (aconselhá-los) e prestigiar-lhes a autoridade. 
A partir do século XI, já na Baixa Idade Média, surgem os indícios de germinação de determinados fenômenos (sociais, intelectuais, econômicos etc.) que auxiliaram na modificação da mentalidade política medieval; período que os historiadores (Cf. Novais, 1997, p. 15) chamam de transição, ou seja, a transformação da sociedade feudal (sagrada) para uma sociedade burguesa (racionalista).

Esse ambiente favoreceu o (re)surgimento do Direito Romano (racionalizado) e a excelência da lei escrita em relação aos costumes. A reintrodução do Direito Romano na Europa ocidental trouxe, a partir do século XII, uma reconstrução e legitimação do Direito Público como se fosse uma das atribuições pessoais dos soberanos e, apesar de os glosadores, também chamados de praxistas, não se interessarem de imediato pelo Direito Penal, foram eles de extrema importância para a tentativa de homogeneização e centralização jurídica nas mãos dos reis e a formação de um Direito nacional já a partir do século XIII (Cf. CARbasse, 2000, p. 122). Nesse sentido, Michel Foucault (2008, p. 180) comenta que:

Um princípio geral no que diz respeito às relações entre direito e poder: parece-me que nas sociedades ocidentais, desde a Idade Média, a elaboração do pensamento jurídico se fez essencialmente em torno do poder real. É a pedido do poder real, em seu proveito e para servir-lhe de instrumento ou justificação que o edifício jurídico das nossas sociedades foi elaborado. No Ocidente, o direito é encomendado pelo rei. Todos conhecem o papel famoso, célebre e sempre lembrado dos juristas na organização do poder real. É preciso não esquecer que a reativação do Direito Romano no século XII foi o grande fenômeno em torno e a partir de que foi reconstituído o edifício jurídico que se desagregou depois da queda do Império Romano. Esta ressurreição do Direito Romano foi efetivamente um dos instrumentos técnicos e constitutivos do poder monárquico autoritário, administrativo e finalmente absolutista.

Importante notar que uma das consequências mais importantes da aplicação da estrutura do Direito Romano pelas monarquias absolutas foi a deslegitimação dos métodos tradicionais de resolução de 
conflitos penais intersubjetivos. Sem o intuito de reduzir outros fatores não menos importantes que possibilitaram o declínio das transações penais privadas no medievo tardio e o aumento da repressão pública (Cf. Rusche; Kichneimer, 2004, p. 25-6), Renée Martinage (1988, p. 14) salienta:

En matière pénale, le droit romain interdit la transaction privée, sauf dans certains cas. Et les commentateurs du droit romain au Moyen Age sont allés plus loin en considérant, à partir du milieu du XIII siècle, que l'accord privé conclu entre les parties n'est pas opposable aux juges. Il s'agissant de lutter contre l'héritage coutumier des compositions pécuniaires. ${ }^{8}$

Michel Foucault (2005, p. 67), contrastando as características da justiça criminal dos primeiros séculos da Idade Média e o surgimento das monarquias medievais, nota que os soberanos passaram a reclamar uma reparação pecuniária dos condenados; não do dano ocasionado como se fossem vítimas, mas como se o Estado fosse violado em seu poder de impor obediência, isto é, o exercício da jurisdição passou a ter uma nítida função disciplinadora e proveitosamente fiscal contra os inimigos políticos. Nessa perspectiva, pode-se notar que um dos mecanismos discursivos utilizados pelo poder estatal para a apropriação dos procedimentos judiciais privados - confrontos e composições entre os indivíduos - foi o estabelecimento da ideia de infração (violação da lei, quebra da ordem), isso para exigir a liquidação dos litígios por intermédio das próprias leis positivadas e instituições formais do soberano:

O soberano, o poder político vêm, dessa forma, dublar e, pouco a pouco, substituir a vítima. Este fenômeno, absolutamente

Livre tradução: "Em matéria penal, o direito romano interditou a transação privada, salvo em certos casos. E os comentadores do direito romano na Idade Média passam a levar mais em consideração, a partir da metade do século XIII, que os acordos privados concluídos entre as partes não podem ser opostos aos juízes. Começam os procedimentos de luta contra a herança consuetudinária das composições pecuniárias." 
novo, vai permitir ao poder político apossar-se dos procedimentos judiciários. O procurador, portanto, se apresenta como o representante do soberano lesado pelo dano.

Como síntese dessas transformações jurídico-políticas, Paolo Grossi (2010, p. 02) lembra que o Direito, tradicionalmente produzido por pessoas privadas na Idade Média para a resolução de situações jurídicas reais, na modernidade passou a estar estreitamente ligado aos detentores do poder político. Isso acabou por provocar a redução das experiências humanas no âmbito jurídico, devido à interdição e não reconhecimento dos métodos tradicionais de resolução de conflitos intersubjetivos, pois o Direito passou a ser conceituado, produzido, controlado e, finalmente confundido com o Estado. Eis o ocaso do que se poderia imaginar Justiça Restaurativa em um mundo que se autodenominou civilizado e representado pelo império da lei.

Com o alastramento do saber iluminista, as teorias jurídicas da modernidade não contestaram a vontade soberana da lei, ao revés, justificaram-no; e até os dias atuais a jurisdição criminal se caracteriza por estar limitada unicamente às normas declaradas pelo Estado - modelo romano -, e aplicada conforme o precioso princípio da legalidade, que é um dos garantes do chamado Estado de Direito. Deveras: nullum crimen, nulla poena sine praevia lege e, porquanto, não há crime sem Estado.

Como salienta Alessandro Baratta (2002, p. 32-3), pode ser constatado na famigerada obra Dos delitos e das penas, de Cesare Bonessana - o Marquês de Beccaria -, um discurso panfletário que exigia a fundação de um Direito Penal que prometesse segurança jurídica individual através da própria lei, isto é: o princípio da legalidade no tocante aos delitos e às penas, baseado no postulado do contrato social e na divisão dos poderes. Deveras, Beccaria (1959, p. 37) promoveu um ataque ao conteúdo do Direito Penal em voga, mas não ao seu modelo juspositivista de legitimação e centralização política da vontade do soberano: "Com efeito, no caso de um delito, há duas partes: o soberano, que afirma que o contrato social foi violado, e o acusado, que nega essa violação." 
No tocante ao que se poderia imaginar de práticas restaurativas, Beccaria se opõe à possibilidade de composição dos danos sofridos pelos ofendidos como uma maneira eficaz de se resolver um conflito penal intersubjetivo. Ao contrário, ele consolida o postulado de que, no âmbito criminal, o soberano é a vítima constante do delito:

Às vezes, a gente se abstém de punir um delito pouco importante, quando o ofendido perdoa. É um ato de benevolência, mas um ato contrário ao bem público. Um particular pode bem não exigir a reparação do mal que se lhe fêz; mas o perdão que êle concede não pode destruir a necessidade do exemplo. O Direito de punir não pertence a nenhum cidadão em particular; pertence às leis, que são o órgão da vontade de todos. Um cidadão ofendido pode renunciar à sua porção dêsse direito, mas não tem nenhum poder sôbre a dos outros. (BeCCARIA, 1959, p. 114)

Dessa forma, pode-se concluir que o ius puniendi, monopólio do Estado contemporâneo, é um discurso jurídico lapidado primorosamente durante os séculos de legitimação dos detentores do poder político (Cf. DAL Ri Júnior, 2006) e centralização dos poderes de coerção aos indivíduos para o controle social, tanto que o Direito Penal hodierno pode ser entendido, também, como uma declaração formal de que as pessoas não possuem o Direito de resolver as suas querelas criminais sem a presença reitora do Estado, que, embora administrado por indivíduos, não permite o exercício da (repudiada) vingança privada, de tal modo que a jurisdição penal é propriedade exclusiva do Estado soberano, que se declara, por intermédio da própria lei positivada - domínio estatal - como sendo a vítima principal, o acusador exclusivo e, por fim, o único que pode aplicar sanções quando violada uma (sua) norma penal.

Enfim, a resolução do conflito penal no âmbito criminal é traduzida pela precisa aplicação da medida punitiva prevista em lei, com uma intensa atividade jurisdicional cogente por parte do Estado. O Direito Penal serve precisamente para punir e não para resolver problemas alheios aos interesses do Estado. 


\section{POSTULADOS INTERNACIONAIS DA JUSTIÇA RESTAURATIVA}

Como alerta Antônio Manoel Hespanha, o discurso dogmático-penal jamais descurou as falhas advindas das normas do Estado soberano. Todavia, utiliza uma linguagem eminentemente crítica como pano de fundo para promover a reforma das normas, constituindo, assim, uma renovação do mito da repressão estatal em prol da ordem pública; inclusive utilizando o sentimento das pessoas em geral como argumento relegitimante das normas criminais. Nas palavras do autor lusitano: "Falar de 'crise da lei' é hoje lugar comum. Claro que nem sempre se trata de um tópico inocente; pelo contrário, muitas vezes nele se insinua um projecto político 'ordeiro'” (Hespanha, 1993, p. 09-10)

Escritos efusivos sobre a necessidade de melhorias na justiça criminal é truísmo nas obras dos juristas, contudo não se encontram propostas de mudança no paradigma estatal monopolizador do exercício da jurisdição penal; ao revés, o aumento geral das penas parece ser a alternativa mais popular adotada pela administração estatal. Em analogia às palavras de Thomas S. Kuhn (2011, p. 126-7) quando se refere às teorias políticas: "As revoluções políticas visam realizar mudanças nas instituições políticas, mudanças essas proibidas por essas mesmas instituições que se quer mudar. Consequentemente, seu êxito requer o abandono parcial de um conjunto de instituições em favor de outro."

Discursos de deslegitimação do velho paradigma punitivo estatal há tempos se despontam no cenário internacional, sendo um dos mais radicais o denominado abolicionismo penal do holandês Louk Hulsmam, que desde a década de 70 do século XX malsina um dos pontos obscuros dos axiomas político-penais da modernidade:

Ao tratarem dos problemas da justiça penal, os discursos políticos, grande parte da mídia e alguns estudiosos da política criminal se põem de acordo e dão a palavra a um determinado 'homem comum'. Este homem comum seria obtuso, covarde e vingativo. Não faria distinção entre marginais, os violentos, os 
molestadores de todos os tipos. Imaginaria as prisões cheias de perigosos assassinos. E veria no aparelho penal o único meio de proteção contra os fenômenos sociais que o perturbam. (Hulsman; Celis, 1993, p. 55)

O autor supracitado também contempla em sua obra exemplos de resoluções alternativas de conflitos penais fora da esfera estatal, que permitiriam a aproximação das pessoas diretamente envolvidas nas situações jurídicas e que prescindiriam de aplicação de punições aflitivas pelo poder público. De maneira lata, Louk Hulsmam pugna pela deslegitimação do discurso oficial do Direito Penal estatal e resgata o ser humano como uma criatura plenamente emancipada, solidária e capaz de resolver os seus problemas sem a tutela cogente do Poder Judiciário. Certamente que as propostas do autor holandês refugem aos postulados mais elementares do Direito Penal contemporâneo, tornando-se o polo oposto - e, portanto, não aceito - do discurso estatal, que monopoliza a seleção e tutela dos bens jurídicos tidos como indispensáveis pelo que se entende, politicamente, como sociedade.

É justamente em uma senda intermediária - que não teria como escopo uma análise crítica da atividade jurisdicional estatal - que se situam as propostas da denominada Justiça Restaurativa. Sobre o surgimento do termo, Renato Sócrates Gomes Pinto comenta:

A denominação justiça restaurativa é atribuída a Albert Eglash, que em 1977, escreveu um artigo intitulado Beyond Restitution: Creative Restitution, publicado numa obra por Joe Hudson e Burt Gallaway, denominada "Restitution in Criminal Justice" (Van Ness e Strong, 2002:27). Eglash sustentou, no artigo, que haviam três respostas ao crime - a retributiva, baseada na punição; a distributiva, focada na reeducação; e a restaurativa, cujo fundamento seria a reparação.

A expressão "justiça restaurativa” acabou por prevalecer em português, embora pareça uma tradução imprópria de "restorative justice", porque, talvez, em língua portuguesa, fosse mais indicada a expressão “justiça restauradora”. (PINTo, 2011, p. 217) 
Paul Mccold e Ted Wachtel (2003) salientam que: “A justiça restaurativa é uma nova maneira de abordar a justiça penal, que enfoca a reparação dos danos causados às pessoas e relacionamentos, ao invés de punir os transgressores."

Howard Zeher reitera o enfoque da JR na reparação dos danos causados pela infração:

Se o crime é um ato lesivo, a justiça significará reparar a lesão e promover a cura. Atos de restauração - ao invés de mais violação - deveriam contrabalancear o dano advindo do crime. É impossível garantir recuperação total, evidentemente, mas a verdadeira justiça teria como objetivo oferecer um contexto no qual esse processo pode começar. (ZeHER, 2008, p. 176)

Raffaella da Porciuncula Pallamolla, por sua vez, pondera que a JR, no Brasil, não possui um conceito definido e sintetiza:

A justiça restaurativa possui um conceito não só aberto como, também, fluido, pois vem sendo modificado, assim como suas práticas, desde os primeiros estudos e experiências restaurativas. $\mathrm{Na}$ década de 70 e 80 (no contexto norte-americano) falava-se em mediação entre vítima e ofensor e reconciliação. Neste momento, a justiça restaurativa estava associada ao movimento de descriminalização. Nos anos 70 encontrava-se em fase experimental e possuía experiências-piloto no sistema penal. Já na década de 80 , tais experiências foram institucionalizadas. $\mathrm{Na}$ década seguinte (anos 90) a justiça restaurativa se expandiu e foi inserida em todas as etapas do processo penal. (Pallamolla, 2009, p. 54-5)

Observa-se, assim, que em um primeiro momento a ideia de JR contemporânea seria a resolução de conflitos intersubjetivos, tendo como pressuposto a ocorrência de um dano criminal entre pessoas e o interesse de que eles fossem reparados, como uma forma de estabelecer a justiça efetiva na comunidade. Mais recentemente - e talvez de maneira contraditória - espera-se que as normas estatais não só reconheçam essas práticas, mas absorvam e regulamentem os processos restaurativos dentro do processo penal. 
Com efeito, a Resolução n ${ }^{\circ}$ 2002/12, editada pelo Conselho Econômico e Social da Organização das Nações Unidas (CESONU), em 24 de julho de 2002, propõe princípios comuns na aplicação de programas de $\mathrm{JR}$ a serem adaptados às práticas processuais criminais por parte dos Estados membros, como, no caso, o Brasil.

Em um primeiro momento, no preâmbulo do anexo da Resolução supracitada obtêm-se a revelação de reconhecimento de que práticas restaurativas são originárias de comunidades tradicionais, que prescindem da noção de Estado para atingirem o ideal de justiça e, de maneira inversa à uma abordagem da História do Direito, que mostra que o Estado interditou as práticas jurídicas das sociedades tradicionais, vaticina-se que a JR seria uma espécie de evolução na Justiça (estatal) criminal: “[...] Enfatizando que a justiça restaurativa evolui como uma resposta ao crime que respeita a dignidade e a igualdade das pessoas, constrói o entendimento e promove harmonia social mediante a restauração das vítimas, ofensores e comunidades, [...]."

Importante, para compreensão da adequação legislativa para a implantação da JR, é o item II, do anexo da Resolução em comento, que preconiza a "Utilização de Programas de Justiça Restaurativa", onde no item II.6 propõe-se que os programas podem ser usados "em qualquer estágio do sistema de justiça criminal". O II.7 aponta para a necessária voluntariedade das pessoas envolvidas no conflito para participação do processo restaurativo e, no item II.11 encontra-se a orientação que, se bem compreendida, indica que o processo restaurativo deve ser realizado fora do âmbito jurisdicional estatal: "Quando não for indicado ou possível o processo restaurativo, o caso deve ser encaminhado às autoridades do sistema de justiça criminal para a prestação jurisdicional sem delonga. [...]”.

Caso os métodos adotados fora do âmbito jurisdicional estatal restarem frutíferos, alcançando-se os resultados almejados, o processo restaurativo deverá ter o mesmo status de qualquer decisão ou julgamento judicial como causa extintiva da punibilidade, impedindo, desta forma, ulterior ação penal acerca do mesmo fato, e perfazendo, 
desta forma, coisa julgada, como se extrai das cláusulas II.15, II.16 e II.17, da Resolução n 2002/12 - CESONU.

Enfim, pelo que se analisa da recomendação normativa internacional, esta reconhece não só a existência, mas também a validade jurídica das práticas e acordos restaurativos e estimula que os Estados, monopolizadores do ius puniendi, as respeitem. Mas, em momento algum confunde-se a JR com as fases pertinentes ao (devido) processo penal no âmbito jurisdicional e é muito clara, a Resolução da CESONU, ao propor um ambiente não jurisdicionalizado para que as partes possam resolver os seus problemas intersubjetivos e comunitários sem ter como escopo a aplicação de uma pena aflitiva prevista em lei.

\section{A JUSTIÇA RESTAURATIVA NA LEGISLAÇÃO BRASILEIRA}

Em 29 de novembro de 2010 o Conselho Nacional de Justiça (CNJ) editou a Resolução no 125 dispondo “[...] sobre a Política Judiciária Nacional de tratamento adequado dos conflitos de interesses no âmbito do Poder Judiciário e dá outras providências.” Em seu texto original não estava contemplada a utilização de métodos consensuais de resolução de conflitos no âmbito criminal. Contudo, com a edição da Emenda no 01, de 31 de janeiro de 2013, surgiu a previsão expressa para inclusão dos Juizados Especiais Criminais nas atividades pertinentes aos Centros Judiciários de Solução de Conflitos e Cidadania. Assim, com o disposto no artigo 7ำ, $\mathbb{\$} 3^{\circ}$, foi apontada a possibilidade de utilização do paradigma internacional da JR no sistema penal pertinente às infrações penais de menor potencial ofensivo:

Art. $7^{\circ}$ omissis.

$[\ldots]$

$\int 3^{\circ}$ Nos termos do art. 73 da Lei no $9.099 / 95$ e dos arts. 112 e 116 da Lei n 8.069/90, os Núcleos poderão centralizar e estimular programas de mediação penal ou qualquer outro processo restaurativo, desde que respeitados os princípios básicos e 
processos restaurativos previstos na Resolução n 2002/12 do Conselho Econômico e Social da Organização das Nações Unidas e a participação do titular da ação penal em todos os atos.

Porém, o referido artigo 73, da Lei no 9.099/95, é norma que concerne à organização judiciária e não ao ius puniendi, não podendo, por si só, permitir as consequências de um acordo restaurativo no âmbito criminal brasileiro.

Explica-se: conforme a competência dada por lei, ao Conselho Nacional de Justiça (CNJ) - criado pela Emenda Constitucional n ${ }^{\circ} 45$, de 30 de dezembro de 2004 - foi concedida "a função de realizar o controle da atuação administrativa e financeira do Poder Judiciário e do cumprimento dos deveres funcionais dos juízes" consoante a redação do artigo $103-\mathrm{B}, \int 4^{\circ}$, da Constituição Federal. Como não possui competência legislativa e suas regras administrativas não podem resultar em modificações em matérias atinentes ao Direito Penal e ao Processo Penal, conforme o princípio da reserva legal estabelecido no artigo 22, caput, parágrafo primeiro e no artigo 24, inciso XI, ambos da Constituição Federal - incluindo, portanto, causas de extinção de punibilidade -, o CNJ não poderia ter tido a iniciativa de orientar a implementação dos postulados internacionais da JR no ordenamento jurídico brasileiro, por lhe faltar competência para tanto (Cf. Paulo; Numazawa, 2016).

De qualquer forma o artigo $7^{\circ}, \mathbb{S} 3^{\circ}$, da Resolução $125 / 2010-$ CNJ, foi alterado pela Emenda n ${ }^{\circ} 2$, de 08 de março de 2016, retirando de seu texto menção à Justiça Restaurativa. Não obstante, rapidamente surgiu outra Resolução, a de n $^{\circ} 225$, de 31 de maio de 2016, do mesmo CNJ, que "Dispõe sobre a Política Nacional de Justiça Restaurativa no âmbito do Poder Judiciário e dá outras providências.” Nessa há uma nova pretensão de se regulamentar a Justiça Restaurativa no âmbito criminal, inclusive com o uso de terminologia própria.

Contudo, já contando com a fata de competência do CNJ para legislar sobre matéria criminal, ainda se observam graves equívocos interpretativos nos termos da Resolução no 225-CNJ, começando em seu preâmbulo: 
$[\ldots]$

CONSIDERANDO que os arts. 72, 77 e 89 da Lei 9.099/1995 permitem a homologação dos acordos celebrados nos procedimentos próprios quando regidos sob os fundamentos da Justiça Restaurativa, como a composição civil, a transação penal ou a condição da suspensão condicional do processo de natureza criminal que tramitam perante os Juizados Especiais Criminais ou nos Juízos Criminais; [...]

Para que pretendesse ter um mínimo de utilidade prática e poder vinculativo às atividades do Poder Judiciário, a Resolução ora analisada deveria respaldar-se com precisão na base legislativa. E isso, à evidência, não ocorreu, porquanto o artigo 72, da Lei nº 9.099/95, exige a presença das partes e do magistrado jurisdicionalmente competente para uma audiência preliminar de conciliação, a ser realizada, obrigatoriamente, perante um Juizado Especial Criminal. Insinuar a existência de uma via paralela à jurisdição, dentro do Poder Judiciário, para os mesmos fins do artigo 72 da Lei $n^{\circ}$ 9.099/95 e simplesmente nomear o ato como se fosse "Procedimento Restaurativo" colocaria em risco o princípio do devido processo legal, pois não foram aclaradas quais seriam as diferenças entre as práticas restaurativas e procedimento preliminar já regulamentado no Juizado Especial Criminal.

Com efeito, no âmbito criminal brasileiro a lei regulamenta a obrigatoriedade de comparecimento do suposto autor dos fatos e vítima (quando houver) ao Juizado Especial Criminal - que é ambiente do Poder Judiciário conforme o artigo 98, inciso I, da Constituição Federal -, como se depreende da redação dos artigos 69, 70 e 71 da Lei n ${ }^{\circ}$ 9.099/95. Não existe voluntariedade nos procedimentos pré-processuais, mas sim obrigações legais e o oferecimento de oportunidades para a composição de danos e aplicação imediata de penas não privativas de liberdade vinculadas à notitia criminis registrada no Termo Circunstanciado.

Ainda, como já visto, a JR tem como fundamento a reparação dos danos sofridos pela vítima e, por isso, seria estranho se pensar em 
processos restaurativos sem a existência de um ser humano ofendido. Pelo artigo $1^{\circ}$, inciso I, da Resolução n ${ }^{\circ} 225-\mathrm{CNJ}$, tanto a vítima quanto a voluntariedade das partes tornam-se estranhamente despiciendas:

Art. $1^{\circ}$. A Justiça Restaurativa constitui-se como um conjunto ordenado e sistêmico de princípios, métodos, técnicas e atividades próprias, que visa à conscientização sobre os fatores relacionais, institucionais e sociais motivadores de conflitos e violência, e por meio do qual os conflitos que geram dano, concreto ou abstrato, são solucionados de modo estruturado na seguinte forma:

I - é necessária a participação do ofensor, e, quando houver, da vítima, bem como, das suas famílias e dos demais envolvidos no fato danoso, com a presença dos representantes da comunidade direta ou indiretamente atingida pelo fato e de um ou mais facilitadores restaurativos;

Como se observa, não há diferenças entre as providências que já são tomadas pelo encaminhamento do Termo Circunstanciado ao Juizado Especial Criminal, decorrente da própria Lei no 9.099/95 e a recomendação do Conselho Nacional de Justiça no que tange ao que se acreditaria ser JR no âmbito crimnal brasileiro. Travestindo-se os princípios internacionais da Resolução 2002/12, da CESONU, como se fossem práticas comuns já existentes há décadas na jurisdição penal brasileira, apenas se intenta dar uma qualificação de fachada aos Juizados Especiais Criminais, como se fossem um ambiente propício de Justiça Restaurativa.

Especificamente sobre a transação penal, regulamentada no artigo 76, da Lei no 9.099/95. que concerne à "aplicação imediata de pena restritiva de direitos ou multas", proposta pelo Ministério Público ao suposto autor dos fatos (KARAN, 2004; Almeida, 2012), além de não corresponder aos princípios internacionais da JR por se tratar de medidas punitivas estatais (Cf. Paulo; Silva, 2014) aplicadas sob os auspícios da simplicidade e informalidade - e prescindir da presença da vítima -, a Resolução $\mathrm{n}^{\circ} 225-\mathrm{CNJ}$ errou ao indicar o instituto 
em comento como se fosse o artigo 77, da Lei dos Juizados Especiais Criminais, atinente este ao momento do início da ação penal e não à transação penal.

Da mesma forma é incompreensível a Resolução no 225-CNJ fazer menção à suspensão condicional do processo nos termos do artigo 89, da Lei n ${ }^{\circ}$ 9.099/95, pois se trata de instituto processual penal expressamente correlato ao sursis (artigos 77 e ss., do Código Penal) que ocorre após o recebimento da denúncia e, malgrado o inciso I, do $\int 1^{\circ}$ do mencionado artigo colocar como condição da suspensão do processo "a reparação do dano, salvo impossibilidade de fazê-lo;" tal obrigação é decorrente da coerção legal para a concessão de um benefício ao acusado e não uma via restaurativa, baseada na voluntariedade, para composição dos danos sofridos pela vítima e comunidade.

Enfim, quais seriam as consequências auferidas com os acordos restaurativos propostos pelo CNJ no Brasil? Como visto, pela Resolução 2002/12-CESONU, no item III. 15, os resultados dos acordos oriundos do processo restaurativo deveriam ter o mesmo status de qualquer decisão ou julgamento judicial, impedindo, inclusive, ulterior ação penal acerca do mesmo fato. Pela Resolução 225-CNJ - que sequer menciona a palavra "resultado" - o artigo 10 registra uma promessa vazia e sem nenhum efeito jurisdicional penal útil às partes:

Art. 10. Logrando-se êxito com as técnicas referidas no artigo anterior, a solução obtida poderá ser repercutida no âmbito institucional e social, por meio de comunicação e interação com a comunidade do local onde ocorreu o fato danoso, bem como, respeitados os deveres de sigilo e confidencialidade, poderão ser feitos encaminhamentos das pessoas envolvidas a fim de atendimento das suas necessidades.

Portanto, em análise aos textos pertinentes à Justiça Restaurativa no âmbito criminal conforme as orientações do CNJ, pode-se concluir que as tentativas normativas existentes apresentam-se como discursos meramente retóricos, simbólicos, imprecisos e sem impacto real na resolução do conflito penal e, sobretudo, não possuem valor 
legal na contemporânea relação cogente entre o ius puniendi estatal e o status libertatis do indivíduo, tendo em vista que estes são regidos por princípios constitucionais que exigem legalidade e respeito ao princípio da reserva legal.

\section{CONCLUSÃO}

Como visto no decorrer do texto, métodos comunitários de resolução de conflitos intersubjetivos pululam na História das sociedades tradicionais, inclusive nas fontes da Europa Ocidental, sendo que a noção de Estado, como detentor exclusivo do ius puniendi é um expediente retórico lentamente lapidado durante os séculos com o uso do discurso legitimador do Direito Romano e uso da violência por parte dos legitimados no poder.

Com a consolidação do saber penal na aurora da Idade Contemporânea, notadamente lastreado em um discurso iluminista legitimador do poder soberano e promotor de uma promessa punitivista geral, igualitária e vedada a interferência de pessoas privadas na administração da justiça criminal, os métodos comunitários e tradicionais de resolução de conflitos foram marginalizados e, finalmente, proibidos, como se observa na rubrica do artigo 345, do Código Penal: "Exercício arbitrário das próprias razões".

Malgrado o surgimento de inúmeras denúncias à ineficiência do discurso oficial do Direito Penal - que está sempre em crise - o Estado tergiversa em seu aparato legal e oferece, como solução à sua própria falta de estrutura, sub-reptícias limitações às garantias fundamentais em prol de respostas baseadas em princípios inconciliáveis no processo penal como a simplicidade, celeridade e informalidade, como é o caso declarado da Lei dos Juizados Especiais Criminais - que é um sucesso em termos de estatísticas jurisdicionais.

Surgidos os discursos sobre uma justiça pautada na resolução de conflitos, visando a reparação dos danos e não tendo como objetivo a 
aplicação de punição ao infrator da Lei do Estado, a Justiça Restaurativa ganhou um ambiente privilegiado no cenário internacional por meio da Resolução 2002/12, da CESONU, propondo orientações gerais para práticas jurídicas que, ao que se compreende em sua redação, ocorreriam fora do âmbito formal da jurisdição estatal; mas que teriam condições de substituí-la e neutralizá-la.

No Brasil, porém, conquanto não tenha competência legislativa para produzir normas que pudessem incidir no Direito Penal e no ius persequendi, o Conselho Nacional de Justiça editou a Emenda $n^{\circ}$ 01, de 31 de janeiro de 2013 na Resolução no 125/2010-CNJ e, posteriormente, editou a Resolução n ${ }^{\circ} 225$, de 31 de maio de 2016, que, além de registrar imprecisões normativas e desnaturar o cerne da proposta internacional de Justiça Restaurativa tentando confundi-la com as fases pré-processuais dos juizados Especiais Criminais, ainda conseguiu desvelar o secular mecanismo de apropriação, ressignificação e vedação dos métodos de resolução de conflitos intersubjetivos que poderiam ocorrer efetivamente na comunidade.

Portanto pode-se concluir que, no Brasil, não existe legislação idônea para práticas de Justiça Restaurativa no âmbito criminal, pois esta teria como finalidade a resolução voluntária dos conflitos entre as pessoas e, como resultado uma declaração de extinção de punibilidade por parte do suposto autor dos fatos. O Conselho Nacional de Justiça, mesmo sem competência legislativa para regulamentar o ius puniendi, apenas assegurou, em seu discurso normativo, que não há reconhecimento de consenso fora do Estado.

\section{REFERÊNCIAS}

ALMEIDA, Vera Ribeiro de. Consenso e verdade na justiça consensual criminal, sob a perspectiva antropológica. In: CONPEDI (Org.). Anais do XXI encontro nacional do CONPEDI - Niterói. Florianópolis: FUNJAB, 2012, p. 25-54. Disponível em: http://www.publicadireito.com.br/ artigos/?cod=7827d1ec626c891d. Acesso em 11 de julho de 2020. 
ALVES, Rubem. Filosofia da ciência: introdução ao jogo e a suas regras. São Paulo: Edições Loyola, 2002.

BARATTA, Alessandro. Criminologia crítica e crítica do direito penal: introdução à sociologia do direito penal. Rio de Janeiro: Revan, 2002.

BATISTA, Nilo. Matrizes ibéricas do sistema penal brasileiro, I. Rio de Janeiro: Revan/ICC, 2002.

BECCARIA, Cesare. Dos delitos e das penas. São Paulo: Atena, 1959.

BIBLIA. Evangelium secundum Matthaeum, 5. S. 1; S. d., Disponível em: https://www.bibliacatolica.com.br/vulgata-latina/evangelium-secundum-matthaeum/5/. Acesso em 11 de julho de 2020.

BURKE, Peter. A escrita na história: novas perspectivas. São Paulo: Unesp, 1992.

CARBASSE, Jean-Marie. Histoire du droit pénal et de la justice criminelle. Paris: Universitaires de France: 2000.

CERAMI, Pietro. Il principato. In: CERAMI, Pietro; CORBINO, Alessandro; METRO, Antonino; PURPURA, Gianfranco. Storia del diritto romano. Messina: Rubbettino, 1996.

CERVO, Amado Luiz; BERVIAN, Pedro Alcino. Metodologia científica: para uso dos estudantes universitários. São Paulo: McGraw do Brasil, 1976.

CICCO, Cláudio de. Direito: tradição e modernidade. São Paulo: Ícone, 1993.

CONSELHO ECONÔMICO E SOCIAL DA ORGANIZAÇÃO DAS NAÇÕES UNIDAS. Resolução 2002/12: Princípios básicos para a utilização de programas de justiça restaurativa em matéria criminal. S.1., 24 de julho de 2002. Tradução livre de Renato Sócrates Gomes Pinto. Disponível em: http://www.juridica.mppr.mp.br/arquivos/File/MPRestaurativoEACulturadePaz/Material_de_Apoio/Resolucao_ONU_2002. pdf. Acesso em 11 de julho de 2020.

DAL RI JÚNIOR, Arno. O estado e seus inimigos: a repressão política na história do direito penal. Rio de Janeiro: Revan, 2006.

FOUCAULT, Michel. A verdade e as formas jurídicas. Rio de Janeiro: NAU, 2005.

FOUCAULT, Michel. Microfísica do poder. Rio de Janeiro: Graal, 2008. 
FOUCAULT, Michel. Arqueologia do saber. Rio de Janeiro: Forense Universitária, 2000.

GROSSI, Paolo. O direito entre poder e ordenamento. Belo Horizonte: Del Rey, 2010.

HESPANHA, Antônio Manoel. Justiça e litigiosidade: história e prospectiva. Lisboa: Fundação Calouste Gulbenkian, 1993.

HULSMAN, Louk; CELIS, Jacqueline Bernat de. Penas perdidas: o sistema penal em questão. Niterói: Luam, 1993.

JUSTINIANUS, Flavius Petrus Sabbatius. Digesto de Justiniano: Líber primus. Tradução de Hélcio Maciel França Madeira. São Paulo: Revista dos Tribunais, 2009.

KARAM, Maria Lúcia. Juizados especiais criminais: a concretização antecipada do poder de punir. São Paulo: RT, 2004.

KUHN, Thomas S.. A estrutura das revoluções científicas. São Paulo: Perspectiva, 2011.

MARTINAGE, Renée. Histoire du droit pénal en europe. Paris: Universitaires de France, 1998.

MCCOLD, Paul; WACHTEL, Ted. Em Busca de um Paradigma: Uma Teoria de Justiça Restaurativa. Trabalho apresentado no XIII Congresso Mundial de Criminologia, 10-15 Agosto de 2003, Rio de Janeiro, Brasil, disponível em: http://www.iirp.edu/article_detail.php?article_id=NTYy. Acesso em 11 de julho de 2020.

MEZZAROBA, Orides; Cláudia Servilha Monteiro. Manual de metodologia da pesquisa no direito: São Paulo: Saraiva, 2004.

MOMMSEN, Teodoro. Derecho penal romano. Santa Fe de Bogotá: Temis, 1999.

NISBET, Robert. Os filósofos sociais. Brasília: UNB, 1982.

NOVAIS, Fernando A. Condições da privacidade na colônia. In: MELLO E SOUZA, Laura de. (org.). História da vida privada no Brasil: cotidiano e vida privada na américa portuguesa. São Paulo: Companhia das Letras, 1997, v.1., p. 13-39.

PALLAMOLLA, Raffaela da Porciuncula. Justiça restaurativa: da teoria à prática. São Paulo: IBCCRIM, 2009. 
PAULO, Alexandre Ribas de.; SILVA, Valine Castaldelli. Justiça restaurativa e transação penal. In: CARVALHO, Érica Mendes (Org.) Direitos fundamentais e sistemas de justiça. Rio de Janeiro: Lumen Juris, 2014, p. 183-210. PAULO, Alexandre Ribas de; NUMAZAWA, Gabriela Natacha Alvares. Uma abordagem constitucional sobre a Justiça Restaurativa no âmbito criminal preconizada na Resolução no 125/2010 do Conselho Nacional de Justiça. Revista da Faculdade de Direito da UFRGS, Porto Alegre, n. 34, p.148-161 - agosto 2016. DOI: https://doi.org/10.22456/0104-6594.62935. PINTO, Renato Sócrates Gomes. A construção da justiça restaurativa no Brasil - o impacto no sistema de justiça criminal. Revista Paradigma, Ribeirão Preto, n. 18, 24 de setembro de 2011. p. 217, 2011.

ROULAND, Norbert. Nos confins do direito: antropologia jurídica da modernidade. São Paulo: Martins Fontes, 2003.

RUSCHE, Georg; KIRCHHEIMER, Otto. Punição e estrutura social. Rio de Janeiro: Revan, 2004.

TÁCITO, Publius Cornélio. Germania. Tradução de João Penteado Erskine Stevenso. Edição bilíngue português/latim. São Paulo: EbooksBrasil, 2001, Disponível em: http://www.ebooksbrasil.org/eLibris/germania.html\#2L. Acesso em 11 de julho de 2020.

VEYNE, Paul. Como se escreve a história; Foucault revoluciona a história. Brasília: UNB, 1998.

WOLKMER Antônio Carlos. História do direito no Brasil. Rio de Janeiro: Forense, 2007.

ZEHR, Howard. Trocando as lentes: um novo foco sobre o crime e a justiça. São Paulo: Palas Athena, 2008.

\section{ALEXANDRE RIBAS DE PAULO}

Graduado em Direito pela Universidade Federal de Santa Catarina (UFSC); Mestre e Doutor em Direito pelo Programa de Pós-Graduação em Direito da Universidade Federal de Santa Catarina (PPGD/ UFSC), na área de Direito, Estado e Sociedade. Realizou Estágio de 
Pós-Doutorado em Direito, Política e Sociedade pelo PPGD/UFSC. Atualmente é Professor Associado TIDE na Universidade Estadual de Maringá (UEM), lotado no Departamento de Direito Privado e Processual (DPP), lecionando a matéria de Direito Processual Penal I. Pesquisador do Ius Commune (Grupo de Pesquisa Interinstitucional em História da Cultura Jurídica - CNPq/UFSC), com ênfase em experiências jurídico-penais medievais e, também, do Grupo de Pesquisa intitulado "Problemas fundamentais do Direito Penal contemporâneo" (UEM). Coordenador do projeto de ensino "Grupo de Investigação sobre Punição (GIP)" e do projeto de extensão "Grupo de Diálogo Universidade-Cárcere-Comunidade (GDUCC)”, ambos da UEM. Endereço profissional: Av. Colombo, 5790 - Zona 7, Maringá - PR, 87020-900, Brasil.

ORCID ID: https://orcid.org/0000-0002-9655-538X

E-MAIL: ribasdepaulo@hotmail.com

\section{VALINE CASTALDELLI SILVA}

Bacharel em Direito da Universidade Estadual de Maringá (20092013). Especialista em Ciências Penais pela mesma universidade (2014-2015). Mestre em Ciências Jurídicas pela Unicesumar (20162017). Doutora (2021) em Direito Internacional, Econômico e Comércio Sustentável pela Universidade Federal de Santa Catarina (UFSC). Pesquisadora vinculada do Grupo de Pesquisa Ius Gentium da UFSC. Docente na UNINGÁ.

Endereço profissional: Rod. PR 317, 6114 Parque Industrial 200, Maringá - PR, 87035-510, Brasil.

ORCID ID: https://orcid.org/0000-0001-6476-899X

E-MAIL: valine_cs@hotmail.com

Recebido: 24/09/2020

Aceito: 08/07/2021 


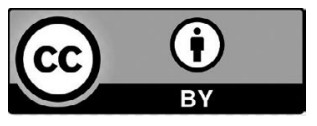

Este trabalho está licenciado sob uma licença Creative Commons Attribution 4.0 International License.

Autores e autoras cedem à Revista Sequência direitos exclusivos de primeira publicação, ficando o trabalho licenciado sob a Creative Commons Attribution 4.0 International License. A licença autoriza que terceiros remixem, adaptem e ou criem a partir do trabalho publicado, indicando o crédito ao trabalho original e sua publicação inicial. Os autores têm permissão para assumir contratos adicionais em separado, com distribuição não exclusiva da versão publicada na Revista Sequência, indicando, de todo modo, a autoria e publicação inicial neste periódico. 